Preprint

UCRL-136379

\title{
Polymeric Carbon Dioxide
}

C.-S. YoO

This article was submitted to

Materials Research Society 1999 Fall Meeting, Boston, MA, November 29 - December 3, 1999

\section{November 2, 1999}

Lawrence

Livermore

National

Laboratory

U.S. Department of Energy

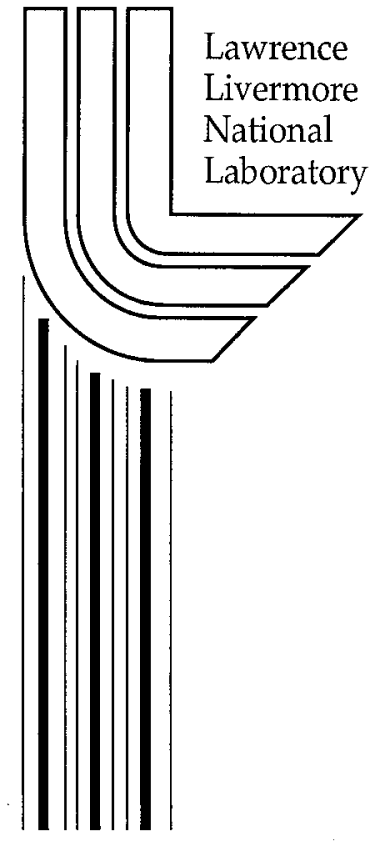




\section{DISCLAIMER}

This document was prepared as an account of work sponsored by an agency of the United States Government. Neither the United States Government nor the University of California nor any of their employees, makes any warranty, express or implied, or assumes any legal liability or responsibility for the accuracy, completeness, or usefulness of any information, apparatus, product, or process disclosed, or represents that its use would not infringe privately owned rights. Reference herein to any specific commercial product, process, or service by trade name, trademark, manufacturer, or otherwise, does not necessarily constitute or imply its endorsement, recommendation, or favoring by the United States Government or the University of California. The views and opinions of authors expressed herein do not necessarily state or reflect those of the United States Government or the University of California, and shall not be used for advertising or product endorsement purposes.

This is a preprint of a paper intended for publication in a journal or proceedings. Since changes may be made before publication, this preprint is made available with the understanding that it will not be cited or reproduced without the permission of the author.

This report has been reproduced directly from the best available copy.

Available to DOE and DOE contractors from the Office of Scientific and Technical Information

P.O. Box 62, Oak Ridge, TN 37831

Prices available from (423) 576-8401 http://apollo.osti.gov/bridge/

Available to the public from the National Technical Information Service

U.S. Department of Commerce 5285 Port Royal Rd., Springfield, VA 22161

http://www.ntis.gov/

OR

Lawrence Livermore National Laboratory

Technical Information Department's Digital Library

http://www.llnl.gov/tid/Library.html 


\title{
POLYMERIC CARBON DIOXIDE
}

\section{CHOONG-SHIK YOO}

Lawrence Livcrmore National Laboratory, Livermore, CA 94551, yoo1 @1lnl.gov

\begin{abstract}
Synthesis of polymeric carbon dioxide has long been of interest to many chemists and materials scientists. Very recently we discovered the polymeric phase of carbon dioxide (called $\mathrm{CO}_{2}-\mathrm{V}$ ) at high pressures and temperatures. Our optical and $\mathrm{x}$-ray results indicate that $\mathrm{CO}_{2}-\mathrm{V}$ is optically non-linear, generating the second harmonic of $\mathrm{Nd}$ : YLF laser at $527 \mathrm{~nm}$ and is also likely superhard similar to cubic-boron nitride or diamond. $\mathrm{CO}_{2}-\mathrm{V}$ is made of $\mathrm{CO}_{4}$ tetrahedra, analogous to $\mathrm{SiO}_{2}$ polymorphs, and is quenchable at ambient temperature at pressures above $1 \mathrm{GPa}$. In this paper, we describe the pressure-induced polymerization of carbon dioxide together with the stability, structure, and mechanical and optical properties of polymeric $\mathrm{CO}_{2}-\mathrm{V}$. We also present some implications of polymeric $\mathrm{CO}_{2}$ for high-pressure chemistry and new materials synthesis.
\end{abstract}

\section{INTRODUCTION}

Application of high-pressure strongly perturbs the nature of chemical bonding, electronic and crystal structures, thermal, mechanical, and optical properties, and chemical reactivities of solids. These perturbations, which often occur systematically, provide opportunities for synthesizing new novel materials. Discoveries of a wide variety of materials unique to high $\mathrm{P}$, T-conditions support this thesis; these include novel-gas compounds [4], metallic hydrogen [5], symmetric ice [6], superhard materials [7], high energy density polymers [8], and alkali-transition metal alloys [9]. Commonly used guidance suggestive to these discoveries has often been inferred from the electronic configuration, intermolecular interaction, crystal structure, effective close-packing and density, solubility and miscibility, group periodicity, and pressure-induced changes of these properties.

Molecular solids are described in terms of strong covalent bonds within molecules and weak van der Waals interactions between molecules. The strong intramolecular bonds make these molecules extremely stable at ambient conditions; whereas, the weak intermolecular interactions make such crystals very soft, at least initially at relatively low pressures. Because of this reason, many simple molecular solids particularly made of the first and second row elements such as $\mathrm{CO}_{2}$, $\mathrm{N}_{2}, \mathrm{C}, \mathrm{H}_{2} \mathrm{O}, \mathrm{CH}_{4}$, other $\mathrm{C}-\mathrm{N}-\mathrm{O}-\mathrm{H}$ compounds are often considered as "inert" at relatively low pressures below $10 \mathrm{GPa}$. In fact, high stabilities of these molecules are often assumed even at very high pressures $(10-40 \mathrm{GPa})$ and temperatures $(1000-5000 \mathrm{~K})$, as $\mathrm{CO}_{2}, \mathrm{~N}_{2}, \mathrm{H}_{2} \mathrm{O}, \mathrm{C}$ are considered to be four major detonation products of energetic molecules.

At high pressures, however, the nature of these intermolecular interactions rapidly alters and becomes highly repulsive. Electron kinetic energy dominates, and electrons localized within intramolecular bonds become unstable. It is due to the higher power dependence of kinetic energy on density, $\rho^{2 / 3}$, than that of potential energy, $\rho^{1 / 3}$ (see Fig. 1). Therefore, at high pressures, the isolated electrons within intramolecular bonds are any longer stable, which leads to delocalization of the electrons through neighboring molecules. Such a modification of chemical bondings clearly results in soften of the stiff repulsive intermolecular potentials at high pressures and thus in physical and chemical phase transformations to a cross-linked two or three dimensional network structures. This perhaps is the reason for which the unsaturated molecular bonds become unstable above $10 \mathrm{GPa}$ and which the network structures are ubiquitous at high pressures as can be seen in diamond, c-BN, $\beta-\mathrm{C}_{3} \mathrm{~N}_{4}$, polymeric $\mathrm{N}_{2}$, etc. $[7,8]$. 
Three mechanisms may occur at high pressures to delocalize electrons and soften repulsive potentials: (i) ionization creating attractive electrostatic energy, (ii) polymerization delocalizing intramolecular electrons between neighboring molecules, and (iii) metallization completely delocalizing electrons through conduction bands. These processes probably occur with increasing pressure as molecular phases $\rightarrow$ ionic species $\rightarrow$ polymeric phases $\rightarrow$ metallic phases. This conjecture is supported by our recent discoveries of the molecular-to-extended ionic and polymeric $\mathrm{CO}_{2}$ phase transitions, both of which occur prior to the metallization at high pressures and temperatures [1-3]. In this paper we will describe the pressure-induced polymerization of $\mathrm{CO}_{2}$ together with its stability, structure, and mechanical and optical properties.

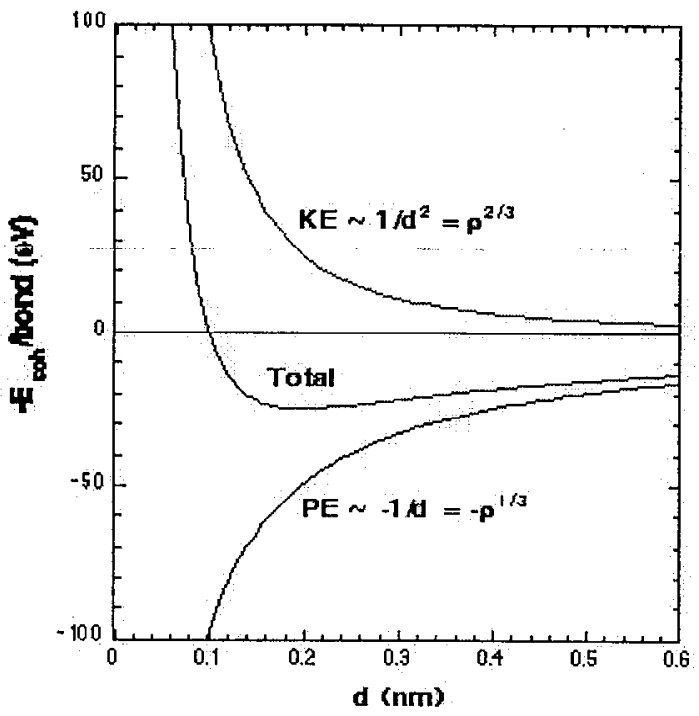

Fig. 1. The change of intermolecular interaction as a function of intermolecular distance (or density).

\section{EXPERIMENT}

The transformations of molecular solids to the extended phases often require relatively large positive volume changes $\left(5-20 \mathrm{~cm}^{3} / \mathrm{mol}\right)$ and, thus, are associated with large kinetic barriers (30-150 $\mathrm{KJ} / \mathrm{mol}$ ) [10]. As a result, these transitions are greatly hindered kinetically despite large thermodynamic stabilities of final products. Nitrogen may be a good example, in which system the polymerization has been suggested theoretically at about $60 \mathrm{GPa}$ [8] but recent experiments indicate nitrogen being molecular even at $120 \mathrm{GPa}$ [11].

In this study, we use a laser-heating technique to overcome the kinetic barrier existing in the molecular-to-extended phase transitions of carbon dioxide. Liquid $\mathrm{CO}_{2}$ was loaded in a diamondanvil cell (DAC) contained in a high-pressure vessel by condensing $\mathrm{CO}_{2}$ gas at $-40{ }^{\circ} \mathrm{C}$ and 10 atmospheres. The polymeric carbon dioxide was synthesized by heating carbon dioxide to high temperatures $(>1800 \mathrm{~K})$ at high pressures $(>35 \mathrm{GPa})$ by using a Nd: YLF laser. However, because of the low absorption of carbon dioxide at the wavelength of Nd:YLF $(1.054 \mu \mathrm{m})$, carbon dioxide was indirectly heated through ruby particles. Temperature of the sample was determined by fitting the thermal emission from the heated-area to a gray-body radiation formula.

The quenched products of $\mathrm{CO}_{2}$ polymerization were investigated by using micro-Raman spectroscopy and synchrotron x-ray diffraction at both ESRF (ID-30) and SSRL (BL10-2). The determination of crystal structure of $\mathrm{CO}_{2}-\mathrm{V}$ has been a challenge due to (I) the incomplete transformation resulting in a mixture phase of $\mathrm{CO}_{2}$-III and $\mathrm{V}$, (ii) relatively low-Z materials, (iii) complex, low symmetry crystal structure, (iv) highly strained lattice with strongly preferred orientation. Despite these difficulties, we were able to obtain reasonable diffraction patterns of various $\mathrm{CO}_{2}$ phases including the polymeric phase by using highly intense $\mathrm{x}$-ray beam at the $3^{\text {rd }}$ generation synchrotron source. With a $10 \mu \mathrm{m}$-size focused monochromatic synchrotron x-ray beam and a fast scanning image-plate detector, we were able to obtain the angle-resolved x-ray diffraction selectively from a nearly completely transformed region of the sample.

The transitions and quenched products of $\mathrm{CO} 2$ were also characterized by micro-Raman spectroscopy using an $\mathrm{Ar}^{+}$-ion laser, a triplemate, and a liq. $-\mathrm{N}_{2}$ cooled $\mathrm{CCD}$ detector. The resolution of this system is within $1 \mathrm{~cm}^{-1}$. 


\section{RESULTS AND DISCUSSIONS}

\section{Molecular Phases of $\mathrm{CO}_{2}$}

Carbon dioxide crystallizes to the cubic $\mathrm{Pa} 3$ structure, $\mathrm{CO}_{2}$-I at $1.5 \mathrm{GPa}$ and ambient temperature [12]. It is optically isotropic as shown in Fig. 2(a). Above $11 \mathrm{GPa}, \mathrm{CO}_{2}-\mathrm{I}$ transforms to the orthorhombic Cmca phase, $\mathrm{CO}_{2}$-III [12], which exists in a wide range of pressures above $70 \mathrm{GPa}$ [3]. The large quadruple moment of linear $\mathrm{CO}_{2}$ molecule is considered to stabilize both $\mathrm{CO}_{2}$-I and III at least at relatively low pressures [13]. However, above $30 \mathrm{GPa}, \mathrm{CO}_{2}$-III develops a very characteristic texture indicative of a highly strained lattice as shown in Fig. 2(b). It also shows an abnormally large pressure gradient exceeding $20 \%$ of the maximum pressure of the sample within $100 \mu \mathrm{m}$. These observations clearly indicate that $\mathrm{CO}_{2}$-III has high material strength at these pressures, which is rather unusual for a molecular crystal. In fact, the bulk modulus of $\mathrm{CO}_{2}$-III has also been found to be unusually high 87 $\mathrm{GPa}$, similar to that of elemental silicon [3]. For comparison, the bulk moduli of molecular phases are typically less than $15 \mathrm{GPa}$. The bulk moduli of various $\mathrm{CO}_{2}$ phases will be discussed in details in the later section below.

\section{Polymeric Phase of $\mathrm{CO}_{2}$}

Above $35 \mathrm{GPa}$ and $1800 \mathrm{~K}$, highly strained $\mathrm{CO}_{2}$-III transforms into a new phase $\mathrm{CO}_{2}-\mathrm{V}$ that can be quenched at ambient temperature as shown in Fig. 2(c). It clearly shows that the texture in transformed area is characteristic from that in untransformed area.

The phase transition from $\mathrm{CO}_{2}$-III to $\mathrm{CO}_{2}-\mathrm{V}$ is also evident from the Raman spectra obtained before and after heating a sample at $40 \mathrm{GPa}$ as shown in Fig. 3. The Raman spectrum of $\mathrm{CO}_{2}$-III is consisted of a few weakly resolved phonons between 250 and $500 \mathrm{~cm}^{-1}$, typical for a highly strained molecular phase [14]. In contrast, the Raman spectrum of $\mathrm{CO}_{2}-\mathrm{V}$ is different from the vibration characteristics of any known molecular polymorph of $\mathrm{CO}_{2}$, suggesting that it has a different structure. We assigned the
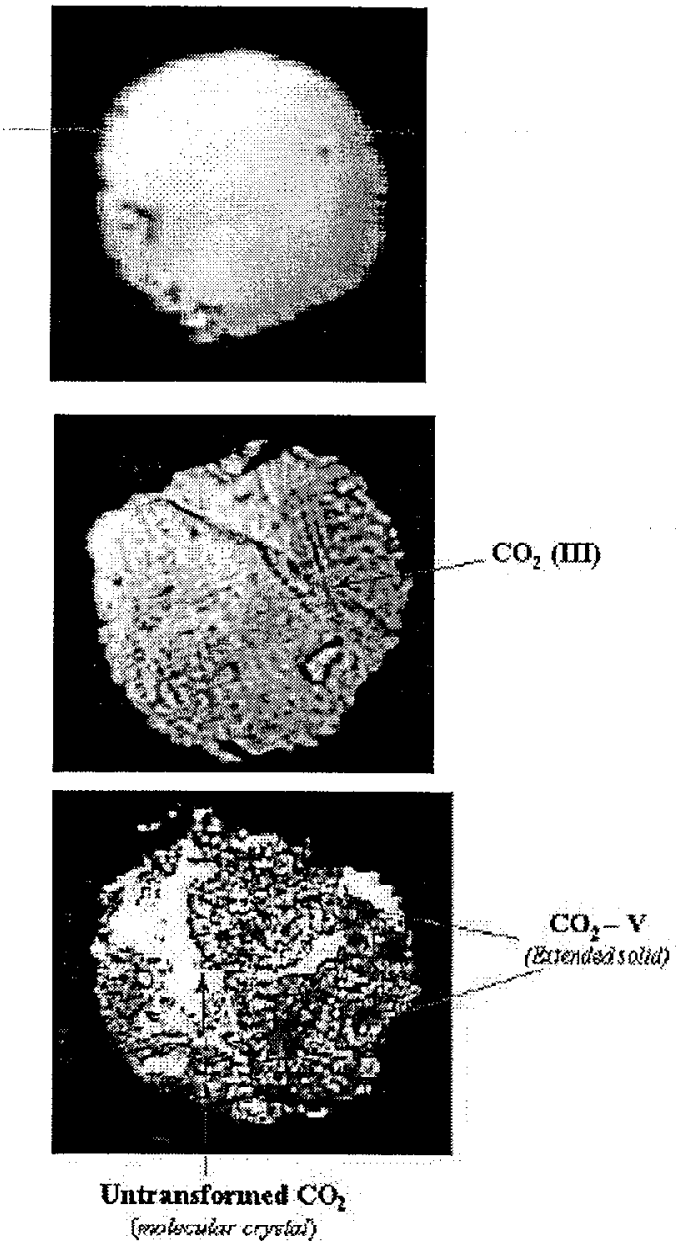

Fig. 2 Crystal phases of carbon dioxide: (a, top) $\mathrm{CO}_{2}-\mathrm{I},\left(\mathrm{b}\right.$, middle) $\mathrm{CO}_{2}$-III, (c, bottom) $\mathrm{CO}_{2}-\mathrm{V} . \mathrm{CO}_{2}$-I and III are molecular phases; whereas, $\mathrm{CO}_{2}-\mathrm{V}$ is an extended polymeric phase (see text).

most dominant vibration feature at $790 \mathrm{~cm}^{-1}$ to the symmetric stretch of the $\mathrm{C}-\mathrm{O}-\mathrm{C}$ bonds, $v_{\sigma}(\mathrm{C}-\mathrm{O}-\mathrm{C})$. Based on the pressure dependence shown in Fig. 4, this mode should be located at $660 \mathrm{~cm}^{-1}$ at ambient conditions of pressure and temperature. This frequency of $v_{\sigma}(\mathrm{C}-\mathrm{O}-\mathrm{C})$ is then translated into $398-491 \mathrm{~cm}^{-1}$ from the $v_{\sigma}(\mathrm{Si}-\mathrm{O}-\mathrm{Si})$ mode in $\mathrm{SiO}_{2}$ polymorphs, depending on the approximation used in the reduced-mass calculation [15]. This mass-weighted vibron frequency agrees reasonably well with $v_{\sigma}(\mathrm{Si}-$ 
$\mathrm{O}-\mathrm{Si}$ ) frequencies in quartz at $464 \mathrm{~cm}^{-1}$ and in coesite at $510 \mathrm{~cm}^{-1}[15,16]$. In contrast, the analogous mode of stishovite, a high-pressure polymorph of $\mathrm{SiO}_{2}$, occurs at $750 \mathrm{~cm}^{-1}$ at ambient conditions [16], even a higher frequency than $v_{s}(\mathrm{C}-\mathrm{O}-\mathrm{C})$ at $660 \mathrm{~cm}^{-1}$ of $\mathrm{CO}_{2}-\mathrm{V}$. The large pressure-dependent shitt of

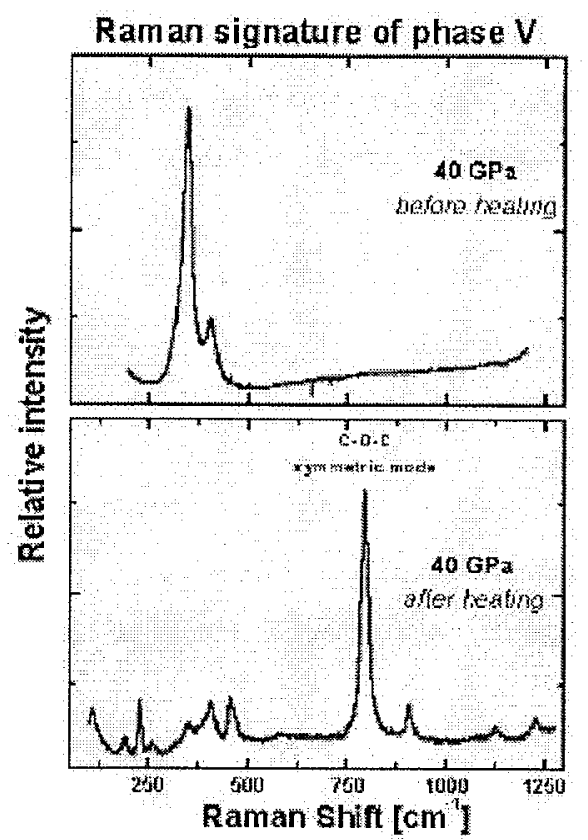

Fig. 3 Raman spectra of $\mathrm{CO}_{2}$ obtained before and after the laser heating at $40 \mathrm{GPa}$, showing the phase transition from molecular $\mathrm{CO}_{2}$-III to polymeric $\mathrm{CO}_{2}-\mathrm{V}$.

\section{Crystal Structure of $\mathrm{CO}_{2}-\underline{V}$}

Figure 5 shows the diffraction pattern of $\mathrm{CO}_{2}-\mathrm{V}$ at ambient temperature during unloading from $48 \mathrm{GPa}$. $\mathrm{CO}_{2}-\mathrm{V}$ is clearly metastable at ambient temperatures over a large pressure range including the entire stability field of $\mathrm{CO}_{2}$-III above $10 \mathrm{GPa}$. Below $10 \mathrm{GPa}, \mathrm{CO}_{2}-\mathrm{V}$ begins to depolymerize to $\mathrm{CO}_{2}$-I; however, diffraction peaks of $\mathrm{CO}_{2}-\mathrm{V}$ remain even at $4 \mathrm{GPa}$. This observation is consistent with the earlier Raman data showing the $\mathrm{C}-\mathrm{O}-\mathrm{C}$ vibration band above $1 \mathrm{GPa}$.

The diffraction pattern of $\mathrm{CO}_{2}-\mathrm{V}$ can be fit in terms of an orthorhombic structure with lattice parameters, $a=6.216 \AA, b=4.352 \AA$, $c$ $=6.066 \AA$ at $48 \mathrm{GPa}$, consistent with 8 molecules per unit cell (Table I).
$v_{s}(\mathrm{C}-\mathrm{O}-\mathrm{C})$ (Fig. 4) also is analogous to that of $v_{\sigma}(\mathrm{Si}-\mathrm{O}-\mathrm{Si})$ in the coesite or quartz polymorphs of $\mathrm{SiO}_{2}$. As previously explained for $\mathrm{SiO}_{2}$ [16-18], the strong shift of $\mathrm{v}_{\sigma}(\mathrm{C}-\mathrm{O}-$ C) implies a high compressibility of $\mathrm{CO}_{2}-\mathrm{V}$ as a result of a large change of $\mathrm{C}-\mathrm{O}-\mathrm{C}$ angles in this open structure.

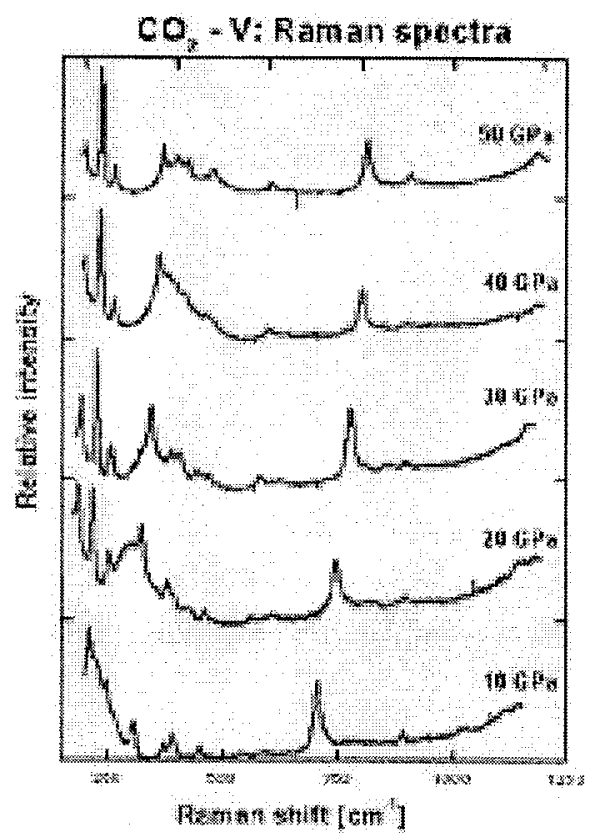

Fig. 4 Raman spectra of $\mathrm{CO}_{2}-\mathrm{V}$ obtained during unloading at ambient temperatures. It shows that the $\mathrm{CO}_{2}-\mathrm{V}$ can be metastably quenched at low pressures above $1 \mathrm{GPa}$.

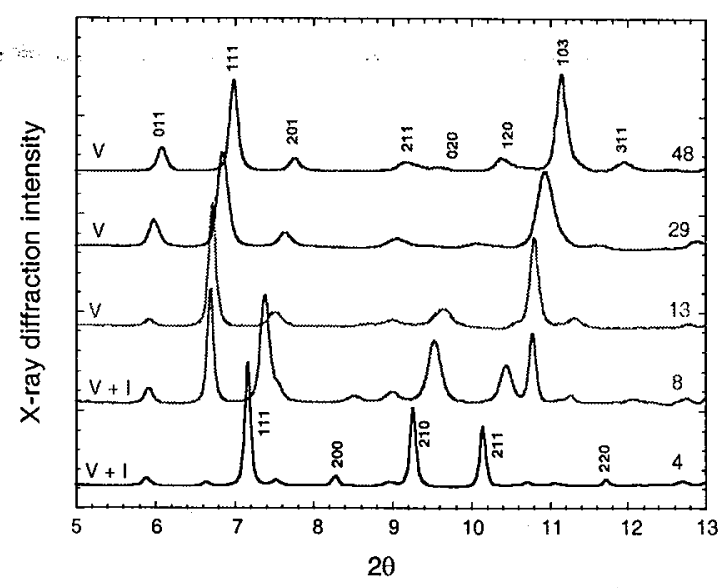

Fig. 5 Angle-resolved $\mathrm{x}$-ray diffraction patterns of $\mathrm{CO}_{2}-\mathrm{V}$ at several high pressures. The numbers indicate the pressures in $\mathrm{GPa}$. 
The intensity data and evidence for preferred orientation do not allow rigorous refinement of the structure. Nevertheless, we found a reasonable description of the diffraction pattern in terms of $\mathrm{SiO}_{2}$-tridymite structures, particularly with an orthorhombic $\mathrm{P}_{1} 2_{1} 2_{1}$ structure that represents about $1 / 3$ of a known $\mathrm{SiO}_{2}$-tridymite unit cell $[19,20]$. The difference in the measured and calculated diffraction intensities was notable particularly for the 103 reflection, probably due to the preferred orientation and/or disorder in the oxygen sublattice of the tridymite structure [21]. In fact, we have verified that introducing a slight disorder into the oxygen positions increases the intensity of the 103 reflection and makes it the strongest.

All tridymite structures can be derived from a parent hexagonal $\left(\mathrm{P}_{3} / \mathrm{mmc}\right)$ structure, a high temperature modification of $\beta-\mathrm{SiO}_{2}$ quartz (P6222), by appropriate rotations of $\mathrm{CO}_{4}$ tetrahedra $[20,21]$. In this "ideal" $\mathrm{P} 22_{1} 2_{1}$ tridymite structure of $\mathrm{CO}_{2}-\mathrm{V}$, each carbon atom is tetrahedrally bound to four oxygen atoms with the carbon-oxygen bond distances between $1.34(0.01)$ at $60 \mathrm{GPa}$ and $1.40(0.01) \AA$ at $10 \mathrm{GPa}$. The O-C-O angles are estimated to be $110(10)^{\circ}$ (Fig. 6). These $\mathrm{CO}_{4}$ tetrahedral units share their corner oxygens to form six-fold distorted holohedral rings with alternating tetrahedral apices pointing up and down the ab plane. The apices of tetrahedra are then connected through oxygen atoms along the c-axis. This interconnected layer structure of tetrahedra yields the C-O-C angle 130(10) ${ }^{\circ}$, substantially smaller than those of $\mathrm{SiO}_{2}$ tridymites, $174^{\circ}-180^{\circ}$.

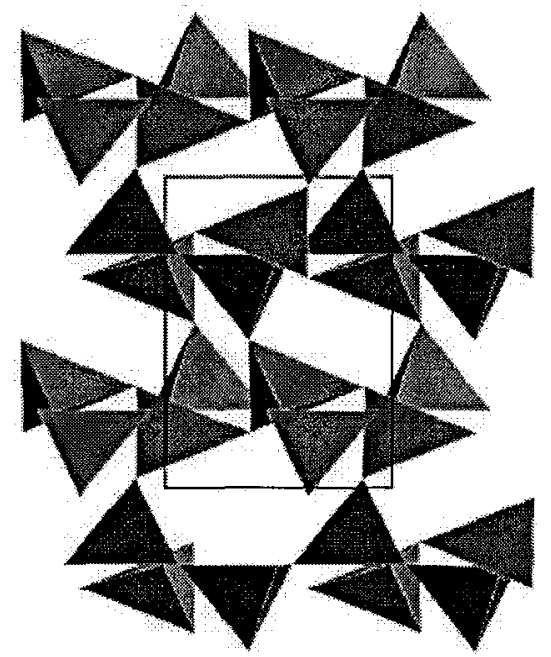

Fig. 6 An "ideal" crystal structure of $\mathrm{CO}_{2}$ $\mathrm{V}$ in $\mathrm{P} 2{ }_{1} 2_{1} 2_{1}$ with 8 molecules per unit cells. Carbon atoms are tetrahedrally bonded to four oxygen atoms, shown as $\mathrm{CO}_{4}$ tetrahedra.

Table I. The crystal structure of $\mathrm{CO}_{2}-\mathrm{V}\left(\mathrm{P} 2_{1} 2_{1} 2_{1}\right)$ at $48 \mathrm{GPa}: \mathrm{a}=6.216 \AA, \mathrm{b}=4.352 \AA, \mathrm{c}=6.066$ $\AA$, and $\rho=3.561 \mathrm{~g} / \mathrm{cm}^{3}$. The calculation was based on eight molecules per unit cell, and the final structure is analogous to that of $\mathrm{SiO}_{2}$-tridymite (see the text).

\begin{tabular}{lrrrrr}
\hline hkl & $\mathrm{d}_{\text {cal }}(\AA)$ & $\mathrm{I}_{\text {cal }}$ & $\mathrm{d}_{\text {obs }}(\AA)$ & $\mathrm{I}_{\text {obs }}$ & $\Delta \mathrm{d}(\AA)$ \\
& & & & & \\
\hline $011 ; 110$ & 3.536 & 20 & 3.531 & 27 & 0.005 \\
$111 ; 200 ; 002$ & 3.074 & 100 & 3.066 & 96 & 0.008 \\
201 & 2.766 & 13 & 2.766 & 17 & 0.000 \\
$211 ; 112$ & 2.335 & 37 & 2.334 & 14 & 0.001 \\
$202 ; 020$ & 2.171 & 14 & 2.161 & 3 & 0.010 \\
$120 ; 021$ & 2.054 & 17 & 2.058 & 18 & -0.004 \\
$103 ; 301 ; 310$ & 1.923 & 33 & 1.923 & 100 & 0.001 \\
311 & 1.788 & 20 & 1.793 & 14 & -0.005 \\
$122 ; 203$ & 1.701 & 12 & 1.700 & 2 & 0.001 \\
\hline
\end{tabular}




\section{Mechanical Properties}

The EOS's of $\mathrm{CO}_{2}$ phases have been determined as a function of pressures as shown in Fig. 7. $\mathrm{CO}_{2}$-I transforms to $\mathrm{CO}_{2}$-III at $12 \mathrm{GPa}$ with no apparent volume discontinuity. The $\mathrm{x}$-ray diffraction patterns between 10 and $20 \mathrm{GPa}$ can be fit in terms of $\mathrm{CO}_{2}$-I and III; no features are apparent for $\mathrm{CO}_{2}-\mathrm{IV}$. This may mean that the structure of $\mathrm{CO}_{2}-\mathrm{IV}$ is similar to that of $\mathrm{CO}_{2}-\mathrm{IIII}$ as suggested by the description, "distorted $\mathrm{CO}_{2}$-III," used in earlier Raman studies [14]. The volume changes associated with this molecular-to-extended (III-to-V) transition vary between $15.3 \%$ at 40 $\mathrm{GPa}$ and $12.6 \%$ at $60 \mathrm{GPa}$, at ambient temperatures. Extrapolations of $\mathrm{CO}_{2}-\mathrm{V}$ and III data yield the volumes 0.322 and $0.453 \mathrm{~cm}^{3} / \mathrm{g}$, respectively.

$\mathrm{CO}_{2}$-I is soft, but both $\mathrm{CO}_{2}$-III and $\mathrm{V}$ are very stiff solids as summarized in Table II. The bulk modulus $\mathrm{B}_{\mathrm{o}}$ of $\mathrm{CO}_{2}-\mathrm{I}$ is 12.4 GPa typical for a molecular solid. In contrast, the $\mathrm{B}_{0}$ of $\mathrm{CO}_{2}$-III is unusually high $87 \mathrm{GPa}$, nearly in the range of $\mathrm{Si}(98 \mathrm{GPa})$ [22]. This result is consistent with the pressure gradient and observed texture in $\mathrm{CO}_{2}$-III (Fig. 2(b)). Furthermore, the nearest neighbor $\mathrm{C}-\mathrm{O}$ distance collapses to $2.303 \AA$ at $40 \mathrm{GPa}$, from $3.135 \AA$ at $1.5 \mathrm{GPa}$. These imply that $\mathrm{CO}_{2}$-III is not entirely molecular; that is, the intermolecular bonding between neighboring $\mathrm{CO}_{2}$ molecules is substantial. Such increased intermolecular bonding in $\mathrm{CO}_{2}$-III at high pressures will certainly increase the strength of this material and act as a precursor for the transition to an extended phase like $\mathrm{CO}_{2}-\mathrm{V}$. The $\mathrm{B}_{\mathrm{o}}$ of $\mathrm{CO}_{2}-\mathrm{V}(365 \mathrm{GPa})$ is much higher than that of $\mathrm{SiO}_{2}$-quartz $(37 \mathrm{GPa})$ or even stishovite ( $310 \mathrm{GPa}$ ) and is comparable to that of cubic-BN (369 GPa) [22]. This high bulk modulus and the large pressure gradient that $\mathrm{CO}_{2}-\mathrm{V}$ supports lead us to conjecture that $\mathrm{CO}_{2}-\mathrm{V}$ is a superhard polymer.

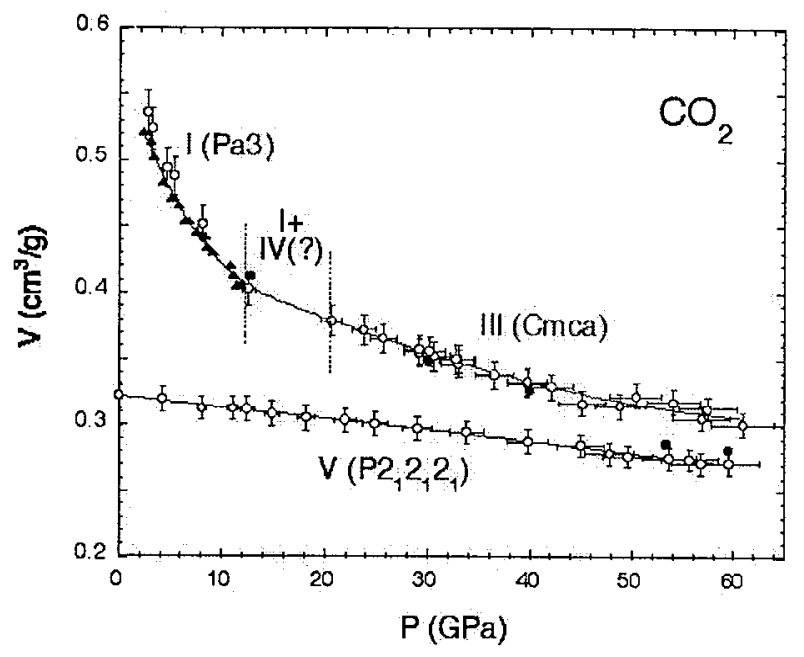

Fig. 7 Pressure-volume relations of $\mathrm{CO}_{2}$ phases. The open circles with error bars are from this study; the solid triangles are from [23]. The calculated volumes of $\mathrm{CO}_{2}-\mathrm{III}$ and $\mathrm{V}$ are also shown as the solid circles. The Birch-Murnaghan fits (lines) yicld $\mathrm{B}_{0}=365$ $\mathrm{GPa}$ for $\mathrm{CO}_{2}-\mathrm{V}, 87 \mathrm{GPa}$ for $\mathrm{CO}_{2}-\mathrm{III}$, and 12 $\mathrm{GPa}$ for $\mathrm{CO}_{2}-\mathrm{I}$.

Table II. The bulk moduli $\mathrm{B}_{\mathrm{o}}$ and their pressurc derivatives B' of $\mathrm{CO}_{2}$ phases in comparison with those of other covalently bonded solids $[24,25]$.

\begin{tabular}{lccc}
\hline \multicolumn{1}{c}{ Soilds } & $\rho\left(\mathrm{g} / \mathrm{cm}^{3}\right)$ & $\mathrm{B}_{\mathrm{o}}(\mathrm{GPa})$ & $\mathrm{B}$ \\
\hline Diamond & 3.50 & 450 & 1.5 \\
cubic-BN & 3.48 & 369 & 4.0 \\
$\mathrm{CO}_{2}$-V & 2.90 & 365 & 0.8 \\
$\mathrm{SiO}_{2}$-Stishovite & 4.30 & 310 & 8.4 \\
$\mathrm{Al}_{2} \mathrm{O}_{2}$-Corrundum & 4.00 & 239 & 0.9 \\
$\mathrm{SiC}$ & 3.22 & 227 & 4.1 \\
$\mathrm{SiO}_{2}$-Coesite & 2.92 & 96 & 8.4 \\
$\mathrm{SiO}_{2}$-Quartz & 2.65 & 37 & 6.2 \\
$\mathrm{Silicon}$ & 2.33 & 98 & 4.2 \\
$\mathrm{CO}_{2}$-III & 2.22 & 87 & 3.4 \\
$\mathrm{CO}_{2}$-I & 1.75 & 12 & 4.5 \\
$\underline{\delta-N}_{2}$ & 1.03 & 3 & 3.9 \\
& & &
\end{tabular}




\section{Optical Properties}

$\mathrm{CO}_{2}-\mathrm{V}$ is also an optically nonlinear solid, generating the second harmonic (SH) of Nd:YLF laser at $527 \mathrm{~nm}$ as shown in Fig. 8. The intensity of this sharp SH-band at $527 \mathrm{~nm}$ depends on how the Nd:YLF output is partitioned between heating and SH generation. The gray-body fit of the broad feature in Fig. 8 indicates that the temperature of the laser-heated area is $1670 \mathrm{~K}$. We estimate the SH conversion efficiency of this new phase to be about $0.1 \%$. The SH radiation was observed in all twenty samples that underwent the transition, indicating that the frequency doubling process is inherent to the new phase and does not rely on trace impurities that may be incorporated in the $\mathrm{CO}_{2}$ lattice during heating. We also consider that the $0.1 \%$ conversion efficiency is remarkably large based on the fact that the conversion efficiency is a nonlinear function of the incident laser power. In this study, we only used $10 \mathrm{~W}$ of a CW laser. Furthermore, the second harmonic was measured from a highly heterogeneous polycrystalline sample at $1670 \mathrm{~K}$ at $45 \mathrm{GPa}$, certainly not an ideal condition for the frequency conversion.

Symmetry considerations for SH generation processes provide further support that the crystal structure of $\mathrm{CO}_{2}-\mathrm{V}$ is noncentrosymmetric like $\mathrm{SiO}_{2}$ tridymite. Strong SH generation of light has been observed in solid forms of $\mathrm{SiO}_{2}$, including crystalline, amorphous, and semiconductor-doped glass with a conversion efficiency up to $20 \%$ $[26,27]$. The relatively sharp phonons and vibrons of $\mathrm{CO}_{2}-\mathrm{V}$ (Fig. 3) imply that $\mathrm{CO}_{2}-\mathrm{V}$ is not vitreous; $\mathrm{SiO}_{2}$ glass is well known to have extremcly broad vibration bands [16]. On the other hand, the SH process is symmetry forbidden in a crystal structure with a center of inversion [28]. This further excludes the possibility of $\mathrm{CO}_{2}-\mathrm{V}$ being a centrosymmetric crystal like coesite or stishovite of $\mathrm{SiO}_{2}[29,30]$. Therefore, it is likely that the structure of $\mathrm{CO}_{2}-\mathrm{V}$ is noncentrosymmetric like those of $\mathrm{SiO}_{2}$-quartz, coesite, or tridymite, supporting the $\mathrm{x}$-ray result. ${ }^{19}$

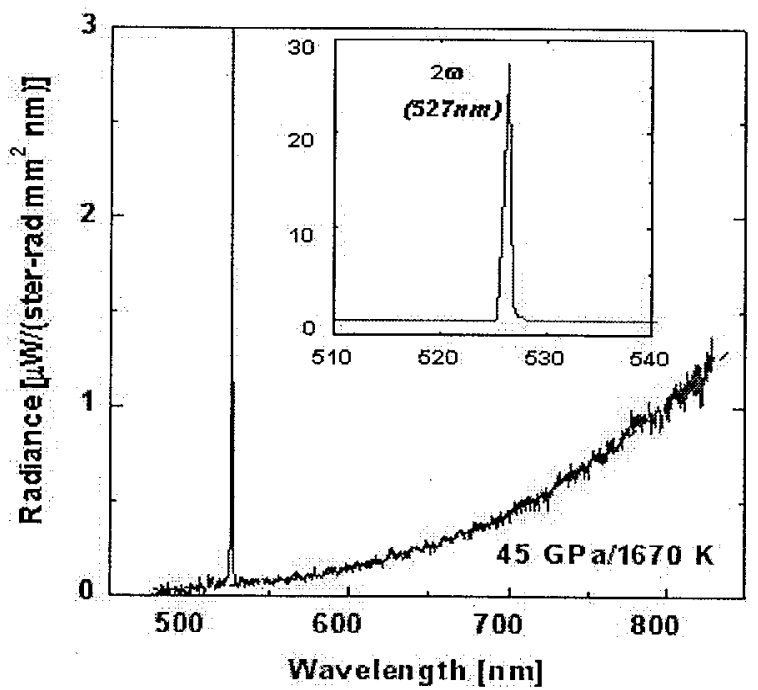

Fig. 8 The emission spectra obtained during $\mathrm{Nd}: Y L F$ laser-heating of $\mathrm{CO} 2-\mathrm{V}$, showing strong the second harmonic emission of the laser at $537 \mathrm{~nm}$ at $1670 \mathrm{~K}$ and $45 \mathrm{GPa}$.

\section{CONCLUDING REMARKS}

We discovered an optically non-linear, superhard polymeric $\mathrm{CO}_{2}-\mathrm{V}$ at high pressures and lemperatures. This is the first discovery of polymer made of $\mathrm{CO}_{4}$ tetrahedra, for which synthesis has been of interest to many chemists and material scientists for many decades. This polymer crystallizes into an orthorhombic tridymite structure above $35 \mathrm{GPa}$ and $1800 \mathrm{~K}$ and can be quenched at ambient temperature above $1 \mathrm{GPa}$. The tridymite structure of $\mathrm{CO}_{2}$ is a high temperature modification of $\beta-\mathrm{SiO}_{2}$ quartz, and there could be other high-pressure modifications of $\mathrm{CO}_{2}$. Those include other four-fold coordinated $\mathrm{CO}_{2}$ phases like cristobalites, quartz and coesites, three-fold carbonates, six-fold stishovite, and even amorphous $\mathrm{CO}_{2}$ glass. The stability of such a wide-range of polymeric $\mathrm{CO}_{2}$ phases if exist is likely strongly dependent on high pressures and temperatures, and the synthesis of such polymorphs in $\mathrm{CO}_{2}$ is clearly a logical step for future sludies.

This new extended polymeric phase of $\mathrm{CO}_{2}$ has very important technological implications for developing high-power optical materials, high strength glass, and energetic materials, especially if it 
can be recovered metastably at ambient pressure. This stems from high thermal conductivity and high energy density expected for this low- $Z$ material. However, these new future material applications of $\mathrm{CO}_{2}$ polymer should cope with several key synthetic new developments, which will be in many regards similar to how the first man-made diamond has been evolved to the largevolume synthesis, dynamic synthesis, and metastable CVD growth. Therefore, our current studies are focused on the recovery of $\mathrm{CO}_{2}-\mathrm{V}$ at ambient condition and the development of alternative synthetic routes including metastable ones.

Carbon dioxide, together with nitrogen, carbon, and $\mathrm{H}_{2} \mathrm{O}$, has been considered to be one of the most stable molecules in a wide range of pressures and temperatures, as these molecules are considered to be four major detonation products of high explosives at 10-50 GPa and 2000-5000 $\mathrm{K}$. The molecular-to-extended phase transition discovered in $\mathrm{CO}_{2}$ is however contradict to the high stability of carbon dioxide and thus provides a new fundamental insight to the stability and structure of many other simple molecules at high pressures and temperatures. In fact, the extended forms of $\mathrm{H}_{2}, \mathrm{~N}_{2}, \mathrm{H}_{2} \mathrm{O}, \mathrm{NH}_{3}, \mathrm{CO}, \mathrm{C}_{2} \mathrm{~N}_{2}, \mathrm{O}_{2}$ have already been experimentally observed and/or theoretically suggested. For example, $\mathrm{N}_{2}$ has been suggested to transform into a polymeric black-P structure above $65 \mathrm{GPa}$ [8]; $\mathrm{C}_{2} \mathrm{~N}_{2}$ and $\mathrm{CO}$ polymerize below $12 \mathrm{GPa}$ even at room temperature [31,32]. The symmetric $\mathrm{H}_{2} \mathrm{O}$ and $\mathrm{NH}_{3}$ recently discovered at high pressures are the extended phases [6,33]. The infrared-active $\mathrm{H}_{2}$-III [34] and $\varepsilon-\mathrm{O}_{2}$ [35] may indicate the initial charge separation between adjacent molecules (e.g. $\mathrm{H}_{2}^{\delta+} \mathrm{H}_{2}^{\delta \cdot}$ and $\mathrm{O}_{2}^{+} \mathrm{O}_{2}^{-}$), precursors to the extended phases. Thus, it is important to insitu investigate the structure and stability of simple molecules at high pressures and temperatures.

\section{ACKNOWLEDGMENTS}

This work has been done in collaboration with V. Iota, H. Cynn, B. Baer, K. Visbeck, F. Gygi, G. Galli, C. Mailhiot at LLNL; M. Nicol (UNLV); D. Hausermann (HP-CAT), S. Carlson (ESRF). The X-ray work reported here has been done at the ESRF and SSRL. This work has been performed under the auspices of the US Department of Energy by the Lawrence Livermore National Laboratory under contract number W-7405-ENG-48. This study has been benefited from the use of synchrotron $x$-ray available at ESRF and SSRL. We recognize the programmatic supports of the work from the PDRP- and LDRD-programs.

\section{REFERENCES}

1. C.S. Yoo, H. Cynn, M. Nicol, submitted (1999).

2. V. Iota, C.S. Yoo, H. Cynn, Science 283, 1510 (1999).

3. C.S. Yoo, et al., Phys. Rev. Lett. (1999) in print.

4. W.L. Vos. L.W. Finger, R.J. Hemley, J.Z. Hu, H.K. Mao, and J.A. Schouten, Nature 358, 46 (1992).

5. S.T. Weir, A.C. Mitchell, W.J. Nellis, Phys. Rev. Lett. 76, 1860 (1996).

6. A.F. Goncharov, V.V. Struzhkin, M.S. Somayazulu, R.J. Hemley, H.K. Mao, Science 273, 218 (1996).

7. A.Y. Liu and M.L. Cohen, Science 245, 842 (1989).

8. C. Mailhiot, L.H. Yang, A.K. McMahan, Phys. Rev. B 56, 140 (1992).

9. L.J. Parker, T. Atou, J.V. Badding, Science 273, 95 (1996). 
10. R. van der Meer, A.L. German, and D. Heikens, J. Poly. Sci. 15, 1765 (1977).

11. H. Lorenzana; a private communication

12. K. Aoki, H. Yamawaki, M. Sakashita, Y. Gotoh, and K. Takemura, Science 263, 356 (1994).

13. R.D. Etters and K. Bogdan, J. Chem. Phys. 90, 4537 (1989).

14. H. Olijnyk and A.P. Jephcoat, Phys. Rev. B 57, 879 (1998).

15. The correspondence between the mode frequencies for the two structures can be estimated by considering the ration of the reduced vibrational masses for the symmetric stretching modes in singly bonded $\mathrm{C}-\mathrm{O}-\mathrm{C}$ and $\mathrm{Si}-\mathrm{O}-\mathrm{Si}$ structures. The angle between the two $\mathrm{X}-\mathrm{O}$ single bonds is chosen to match the bond angle in $\alpha$-quartz $\left(104.6^{\circ}\right)$. The low frequency limit (398 $\mathrm{cm}^{-1}$ ) results from considering isolated structures ( $\mathrm{X}_{2} \mathrm{O}$ molecules) while the upper frequency $\left(491 \mathrm{~cm}^{-1}\right)$ results by considering the second order shell of $\mathrm{O}$ atoms moving rigidly with the $\mathrm{C}$ (Si).

16. R.J. Hemley, in High Pressure Research in Mineral Physics, edited by M. H. Manghnani and Y. Syono, pp 347, (Terra Sci. Pub. Co., Tokyo, 1987).

17. S.K. Sharma, J.F. Mammone, M.F. Nicol, Nature 292, 140 (1981).

18. J.D. Jorgensen, J. Appl. Phys. 49, 5473 (1973).

19. A.K.A. Pryde and M.T. Dove, Phys. Chem. Minerals, 26, 171 (1998).

20. R.F. de Dombal and M.A. Carpenter, Eur. J. Mineral 5, 607 (1993) and references therein.

21. H. Graetsch and O.W. Flörke, Zeitschrift für Kristallographic 195, 31 (1991).

22. E. Knittle, "Mineral Physics and Crystallography, a Handbook of Physical Constants" Edited by Ahrens, T., pp 98-142 (AGU, 1995); Knittle et al., Nature 337, 349 (1989).

23. B. Olinger, J. Chem. Phys. 77, 6255 (1982).

24. E. Knittle, "Static Compression Measurements of Equation of State" in "Mineral Physics and Crystallography, a Handbook of Physical Constants" Edited by Ahrens, T., pp 98-142 (AGU, 1995) and the references therein.

25. E. Knittle, R.M. Wentzcovitch, R. Jeanloz, M.L. Cohen, Nature 337, 349 (1989).

26. T.J. Driscoll and N.M. Lawandy, J. Opt. Soc. Am. B11, 355 (1994).

27. Y. Sasaki and Y. Ohmori, Appl. Phys. Lett. 39, 466 (1981).

28. In general, the second harmonic of light is generated in non-centrosymmetric crystals; whereas, only odd harmonic are observed in centrosymmetric crystals. This stems from the second order polarization dependence of electromagnetic transitions. In crystals having a center of symmetry, the inversion of all coordinates must leave all relationships between physical quantities unchanged. Because the electric field $\mathbf{E}$ is odd under inversion operations, the polarization field $\mathbf{P}$ must also be odd, and the coefficients of all even powers in the 
expansion of the polarization: $\mathbf{P}=\varepsilon_{0} \chi_{1} \mathbf{E} \sin (\omega t)+\varepsilon_{0} \chi_{2} \mathbf{E}^{2} \sin ^{2}(\omega t)+\varepsilon_{0} \chi_{3} \mathbf{E}^{3} \sin ^{3}(\omega t)+\ldots$ must vanish. In such crystals, only odd multiples of the incident frequency can be generated.

29. R.W.G. Wyckoff in Crystal Structures, vol 1, 2nd ed., pp 467 (Intersci., New York, 1963).

30. S.M. Stishov and V. Popova, Geochem, Eng. Trans. 10, 923 (1961).

31. C.S. Yoo and M.F. Nicol, J. Phys. Chem. 90, 6726 (1986); ibid 90, 6732 (1986).

32. A.I. Katz, D. Schiferl, and R.L. Mills, J. Phys. Chem. 88, 3176 (1981).

33. M. Gauthier, P. Pruzan, J.C. Chervin, and J.M. Besson, Phys. Rev. B 37, 2102 (1988).

34. M. Hanfland, R.J. Hemley, H.K. Mao, Phys. Rev. Lett. 70, 3760 (1993).

35. Y. Akahama, H. Kawamura, S. Carlson, T. Le Bihan, and D. Hasermann, the abstract in a proceedings to the AIRAPT-17, Hawaii, July 25-30, 1999, p72; also L. Ulivi, R. Bini, F. Gorelli, M. Santoro, ibid, p73. 